personality disorder is for well-resourced teams that should use well-integrated psychological interventions but that these should not be brief (i.e. of less than 3 months' duration). This is all well but these specialist teams will be costly to develop and maintain. Is there the stomach to fund these across the piece and is there capacity among the workforce to deliver what NICE recommends?

\section{Conclusions}

Not wishing to end on too negative a note, there is one professional who is suitably trained to manage complex cases and that is the general psychiatrist. Given that those with personality disorder will present not only with personality difficulties but with many other Axis I conditions that will be more resistant to conventional treatments because of the personality disorder, the full panoply of interventions - both pharmacological and psychological - will be required and properly sequenced. Is this not a tailor-made opportunity for psychiatrists to embrace under the New Ways of Working? Were this to occur, having a diagnosis of personality disorder would no longer be a reason for being excluded from services. This would be welcome and when it occurs, I suspect there will still be a place for medication, albeit on a more rational basis than is currently the case. Baker-Glenn et al's paper draws our attention to some of the many unanswered questions in this important area of psychiatric practice. It is high time for us to address these areas of ignorance!

\section{About the author}

Conor Duggan is Professor of Forensic Mental Health, University of Nottingham, and Honorary Consultant Psychiatrist, Nottinghamshire Healthcare NHS Trust.

\section{References}

1 National Institute for Health and Clinical Excellence. Borderline Personality Disorder: Treatment and Management. The British Psychological Society and The Royal College of Psychiatrists, 2009.

2 Tyrer P, Mitchard S, Methuen C, Ranger M. Treatment-rejecting and treatment-seeking personality disorders: Type R and Type S. J Pers Disord 2003; 17: 265-70.

3 Swanson MC, Bland RC, Newman SC. Epidemiology of psychiatric disorders in Edmonton. Antisocial personality disorders. Acta Psychiatr Scand Suppl 1994; 376: 63-70.

4 Sanderson C, Clarkin JF. Further use of the NEO-Pi-R personality dimensions in differential treatment planning. In Personality Disorders and the Five Factor Model of Personality (2nd edn) (eds PT Costa, TA Widiger): 351-75. American Psychological Association Books, 2002.

5 Soloff $\mathrm{PH}$. Symptom-orientated psychopharmacology for personality disorders. J Practical Psychiatr Behav Health 1998; 4: 3-11.

6 Reich JH, Green Al. Effect of personality disorders on outcome of treatment. J Nerv Ment Dis 1991; 192: 74-82.

\title{
Long-term follow-up of individuals on assertive outreach teams
}

\author{
Tanvir Rana, ${ }^{1}$ Martin Commander ${ }^{2}$
}

The Psychiatrist (2010), 34, 88-91, doi: 10.1192/pb.bp.108.022764

\begin{abstract}
${ }^{1}$ South Staffordshire and Shropshire Healthcare NHS Foundation Trust, Stafford; ${ }^{2}$ Birmingham and Solihull Mental Health Trust, Birmingham

Correspondence to Martin Commander (martin.commander@bsmhft.nhs.uk)
\end{abstract}

Aims and method To describe the long-term outcome of 165 people taken onto
assertive outreach teams. Results After a mean follow-up of 6 years and 8 months, 130 people remained in contact with local services of whom 100 were still under the care of an assertive outreach team. Admission rates remained around half those at inception. However, 16 individuals had died, 10 spent time in prison, 12 were homeless and 14 had protracted stays in hospital during the follow-up period.

Clinical implications Although assertive outreach teams are successful in engaging individuals and reducing admission rates, these benefits plateau after the first few years and could possibly be sustained by other services that may in addition focus more on those areas where teams have proven less effective including physical health, housing and employment.

Declaration of interest None.
The introduction of assertive outreach teams has been a central pillar of UK mental health policy in recent years. ${ }^{1}$ These teams focus on people with severe and enduring mental illness who have high levels of bed usage and are typically disaffected with services. Although they have been successful in engaging individuals and improving satisfaction, ${ }^{2}$ there is uncertainty about their ability to reduce demand on in-patient care, and findings with respect to 


\begin{tabular}{|c|c|c|}
\hline \multirow[b]{2}{*}{ Variable } & \multicolumn{2}{|c|}{ Participants $(n=130)$} \\
\hline & $n$ & $\%$ \\
\hline \multicolumn{3}{|l|}{ Age, years } \\
\hline $16-24$ & 2 & 1 \\
\hline $25-44$ & 105 & 81 \\
\hline $45-64$ & 23 & 18 \\
\hline Gender, male & 94 & 72 \\
\hline \multicolumn{3}{|l|}{ Ethnicity } \\
\hline Asian & 9 & 7 \\
\hline Black & 61 & 47 \\
\hline White & 50 & 39 \\
\hline Other & 10 & 7 \\
\hline \multicolumn{3}{|l|}{ Diagnosis } \\
\hline \multicolumn{3}{|l|}{ Schizophrenia, schizotypal } \\
\hline or delusional disorder & 92 & 71 \\
\hline Bipolar disorder & 33 & 25 \\
\hline Other & 5 & 4 \\
\hline \multicolumn{3}{|l|}{ Team } \\
\hline Same assertive outreach team & 94 & 72 \\
\hline Different assertive outreach team & 6 & 5 \\
\hline Rehabilitation and recovery team & 17 & 13 \\
\hline $\begin{array}{l}\text { Primary care liaison team/community } \\
\text { mental health team }\end{array}$ & 13 & 10 \\
\hline
\end{tabular}

symptomatology and social functioning have been disappointing. ${ }^{3,4}$ Furthermore, little is known about what happens to people on assertive outreach teams in the longer term. In particular, the ability of these teams to overcome perceived shortcomings in community care, notably increased homelessness, imprisonment and mortality, remains uncertain. In north Birmingham, assertive outreach teams were routinely introduced as part of a comprehensive strategy for integrated community-based services in the mid- to late 1990s. The sustained implementation of these teams offers the opportunity to evaluate the longer-term impact of assertive outreach in the UK.

\section{Method}

As a result of limited resources it was only possible to include individuals from three of the five eligible assertive outreach teams in the follow-up. The teams operated according to the model laid out in the Department of Health Implementation Guidelines ${ }^{1}$ and have been described in detail elsewhere. ${ }^{3}$ In addition to two or more admissions/home treatment episodes in the past 2 years, it was expected that participants would fulfil three or more of the following criteria: a history of persistent offending or violence; at risk of persistent self-harm or neglect; a failure to respond to treatment; comorbid substance misuse; and a history of compulsory detention.

Initial data were collected between 1999 and 2002 for each individual as they were recruited onto the assertive outreach teams and again 2 years after entry into the service (for further details see Commander et al). ${ }^{3}$ The additional follow-up data reported here were subsequently obtained through hospital case records and interviews with care coordinators. A simple proforma was developed to ensure uniform data collection. The variables included housing and employment, violence and imprisonment, admission and medication, current psychiatric team and engagement with services. Data were analysed using the Statistical Package for Social Sciences 12.01 for Windows. The chi-squared test was used to compare different groups within each time point. The Cochrane (for categorical data) and Friedman's tests (for ranked data) were used to compare paired findings for each individual across the three time points.

\section{Results}

Of the 165 eligible individuals, 130 (79\%) were in contact with local services at follow-up. Of the remaining 35 individuals ( 13 of whom were under different teams at the time of their last contact), 6 had been discharged to a general practitioner in Birmingham, 9 had moved out of the city and 4 were impossible to trace. The remaining $16(10 \%)$ were deceased. One died of an overdose of street drugs in his flat, another choked to death shortly following an intramuscular injection on a psychiatric ward and a third died of a pulmonary embolism in a general hospital secondary to a fractured ankle sustained when jumping off an elevated road junction. One death remained under investigation by the coroner at the time of data collection and of the remaining individuals, three died of carcinoma and seven of cardiovascular disease.

The characteristics of the 130 participants still known to services are presented in Table 1. Middle-aged men with non-affective psychotic disorders predominated and notably almost half were identified as of Black ethnic group. The mean follow-up period for these individuals was 6 years and 8 months (s.d. $=7$ months). One hundred participants (77\%) were still under the care of an assertive outreach team. Of the 30 people who were now under other teams, there was a median 5 years (mean 59 months (s.d. = 18), data missing for 5 people) since their change of team. One person currently on an assertive outreach team had been transferred to a different team but subsequently returned. During the follow-up period only two people had an unplanned loss of contact with services lasting more than 3 months. All 130 individuals were currently in regular contact with services, although 3 had refused prescribed medication during the previous month. When compared with data from the baseline assessment, these findings indicate a sustained improvement in cooperation with services albeit one that was evident at the initial 2-year follow-up (Table 2).

Ten individuals (8\%) spent time in prison during the follow-up period for stays of between 1 and 10 months (median 3 months). This showed little change over time (Table 2). Thirty participants (23\%) were involved in episodes of violent behaviour (defined as the person being involved in a fight, hitting or otherwise assaulting someone) during the follow-up period. Of these incidents, 27 involved the use of hands or other parts of the body, 2 the use of an object such as a chair, and 1 an offensive weapon (a knife). Minor injury (requiring first aid) was caused in 25 instances, moderate (needing some medical attention) in 4 , and 1 incident resulted in serious injury. Four individuals (3\%) had spent time, and indeed remained, in a medium secure unit.

Homelessness (defined as using a homeless hostel/ shelter or rough sleeping) was experienced by 12 people 
(9\%) during the follow-up period and was currently the case for $7(5 \%)$ individuals. Employment was extremely low across all three time points and independent living decreased by comparison with baseline findings (Table 2).

Fourteen people (11\%) had been in hospital for a stay lasting longer than 6 months during the follow-up period (median 17 months, range from 7 to 49). At the time of data collection, 8 (6\%) participants had currently been in hospital for more than 6 months (median 20 months, range from 9 to 49). The number of admissions including those under the Mental Health Act remained around half the level found prior to entry into the service as did total bed days used (for the 114 participants with related data from each time point 15527 days at baseline, 8571 (55\% of baseline) at 2 years and 8353 (54\% of baseline) at follow-up; Table 2).

When the 30 individuals who had moved onto and remained with other teams were compared with those remaining on assertive outreach they were significantly less likely to have been admitted in the 2 years up to the final follow-up ( $3 \%$ v. $\left.52 \%, \chi^{2}=22.63, P<0.0001\right)$ including under the Mental Health Act ( $3 \%$ v. $\left.42 \%, \chi^{2}=15.59, P<0.0001\right)$.

\section{Discussion}

There are obvious limitations with this study. It was undertaken in an urban setting, Birmingham, which has a population of just over a million people (of whom $30 \%$ are from an ethnic group other than White (www.birmingham. gov.uk/) and is ranked the fifteenth most deprived local authority in England (Index of Multiple Deprivation 2004, www.communities. gov.uk). The need to confine the sample to three out of five eligible teams for logistical reasons as well as the lack of data on people no longer in contact with local psychiatric services restricts the generalisibility of the findings. Furthermore, the follow-up data encompass only major events likely to be accurately recalled by staff or recorded in the case notes. Nevertheless, the study has notable strengths with respect to the substantial sample size, the lengthy time period covered and the considerable follow-up rate.

The high level of sustained contact with services and low level of disengagement is striking and reinforces a conviction that assertive outreach teams are able to retain people within psychiatric services. By way of contrast, the (natural) death rate is a matter for concern and challenges teams to do far more to ensure satisfactory physical healthcare is provided to people whose access to general practice may be poor. Imprisonment remained consistently low and few individuals were detained in a medium secure unit during the follow-up period. Nevertheless, almost a quarter of participants were involved in violent incidents, reinforcing the need for staff training and support in risk assessment/management. ${ }^{5}$

The consistently low level of employment across the follow-up period is disappointing. Although this lends credence to criticisms that assertive outreach teams are insufficiently focused on social inclusion goals, ${ }^{6}$ it may also reflect disincentives generated by enhanced access to benefits as well as the fluctuating yet substantial and ongoing distress, disability and disruption experienced by this cohort of individuals. Homelessness was an issue for a significant minority and may have been higher as temporary lodging with friends or relatives was not included. Furthermore, over a third of participants remained living in congregate settings such as hostels and group homes rather than obtaining their own homes. This finding may reflect the difficulties in housing people with histories of antisocial behaviour and substance misuse. It is also notable that one in ten people remained in hospital for protracted

\begin{tabular}{|c|c|c|c|c|c|c|}
\hline Variable & $\begin{array}{c}n \\
\text { paired } \\
\text { data }\end{array}$ & Baseline & $\begin{array}{l}\text { 2-year } \\
\text { follow-up }\end{array}$ & $\begin{array}{l}\text { Long-term } \\
\text { follow-up (mean } \\
6 \text { years } 8 \text { months) }\end{array}$ & Statistical test & $P$ \\
\hline $\begin{array}{l}\text { Unplanned disengagement past } \\
\text { month, } n(\%)\end{array}$ & 122 & $12 / 129(9)$ & $4 / 123(3)$ & $0 / 130(0)$ & Cochrane's $Q=14.93$ & 0.001 \\
\hline $\begin{array}{l}\text { Discontinuation of medication } \\
\text { past month, } n(\%)\end{array}$ & 113 & $28 / 129(22)$ & $8 / 113(7)$ & $3 / 130(2)$ & Cochrane's $Q=26.61$ & $<0.001$ \\
\hline Prison in past 2 years, $n(\%)$ & 122 & $6 / 122(5)$ & $3 / 123(2)$ & $5 / 130(4)$ & Cochrane's $Q=1.08$ & 0.58 \\
\hline $\begin{array}{l}\text { Physical harm to others in past } \\
\text { month, } n(\%)\end{array}$ & 122 & $3 / 129(2)$ & 4/123 (3) & $4 / 130(3)$ & Cochrane's $Q=0.22$ & 0.90 \\
\hline In work, n (\%) & 122 & $7 / 129(5)$ & $2 / 123(2)$ & $4 / 130(3)$ & Cochrane's $Q=3.71$ & 0.16 \\
\hline $\begin{array}{l}\text { Independent accommodation, } \\
n(\%)\end{array}$ & 118 & $93 / 130(72)$ & $80 / 118(62)$ & $78 / 130(60)$ & Cochrane's $Q=8.07$ & 0.02 \\
\hline Admission in past 2 years, $n(\%)$ & 124 & 102/124 (82) & $65 / 126(52)$ & $53 / 130(41)$ & Cochrane's $Q=52.02$ & $<0.001$ \\
\hline $\begin{array}{l}\text { Compulsory admission in past } \\
2 \text { years, } n(\%)\end{array}$ & 118 & $80 / 118(68)$ & $50 / 126(40)$ & 43/130 (33) & Cochrane's $Q=34.99$ & $<0.001$ \\
\hline $\begin{array}{l}\text { Number of admissions in past } \\
2 \text { years, median ( } 2.5-97.5 \\
\text { percentiles) }\end{array}$ & 124 & $1.0(0.0-5.0)$ & $1.0(0.0-3.8)$ & $0.0(0.0-3.0)$ & Friedman's $=49.54$ & $<0.001$ \\
\hline $\begin{array}{l}\text { Number of compulsory admissions } \\
\text { past } 2 \text { years, median }(2.5-97.5 \\
\text { percentiles) }\end{array}$ & 118 & $1.0(0.0-3.0)$ & $0.0(0.0-2.0)$ & $0.0(0.0-2.7)$ & Friedman's $=36.68$ & $<0.001$ \\
\hline $\begin{array}{l}\text { Days in hospital in past } 2 \text { years, } \\
\text { median }(2.5-97.5 \text { percentiles })\end{array}$ & 114 & $81.5(0.0-720.0)$ & $4.0(0.0-566.3)$ & $0.0(0.0-668.8)$ & Friedman's $=28.63$ & $<0.001$ \\
\hline
\end{tabular}


periods reinforcing the need for suitable longer-term intensively staffed facilities in the community.

There was a sustained reduction in admissions but the gains appeared to plateau after the initial 2 years raising questions about the ongoing value of assertive outreach teams. As originally conceived, the teams' intervention was intended to be indefinite and the argument made that gains would be lost once the service was withdrawn. However, this position has become increasingly contentious. Indeed, the philosophy of 'no discharge' may be to the detriment of both individuals and services. ${ }^{5}$ In this study only one person left and then returned to an assertive outreach team, whereas admission rates were lowest for people transferred to other teams. Although indicating that people can do well on moving to less intensive services, this may have been anticipated given the people's perceived suitability for transfer. However, it is possible, given the plateau effect seen here after the first 2 years, that turnover of people on assertive outreach case-loads is too low (less than $5 \%$ per year here) and suggests that teams need to give more emphasis to exit strategies and set targets for moving on. ${ }^{5}$

\section{About the authors}

Tanvir Rana is a consultant psychiatrist at the South Staffordshire and Shropshire Healthcare NHS Foundation Trust, Stafford, and Martin Commander is a consultant psychiatrist at Birmingham and Solihull Mental Health Trust, Northcroft, Birmingham

\section{References}

1 Department of Health. The Mental Health Policy Implementation Guide. Department of Health, 2001.

2 Killaspy H. Assertive community treatment in psychiatry. BMJ 2007; 335: 311-2.

3 Commander M, Sashidharan S, Rana T, Ratnayake T. North Birmingham assertive outreach evaluation. Patient characteristics and clinical outcomes. Soc Psychiatry Psychiatr Epidemiol 2005; 40: 988-93.

4 Killaspy $\mathrm{H}$, Bebbington $\mathrm{P}$, Blizard $\mathrm{R}$, Johnson $\mathrm{S}$, Nolan $\mathrm{F}$, Pilling $\mathrm{S}$, et al. The REACT study: randomised evaluation of assertive community treatment in north London. BMJ 2006; 332: 815-8.

5 Burns T, Firn M. Assertive Outreach in Mental Health - A Manual for Practitioners. Oxford University Press, 2002.

6 Priebe S. Institutionalisation revisted - with and without walls. Acto Psychiatr Scand 2004; 110: 81-2.

\title{
Improving physical health monitoring for out-patients on antipsychotic medication
}

\author{
Carlos Gonzalez, Niyaz Ahammed, ${ }^{2}$ Robert Fisher $^{3}$
}

The Psychiatrist (2010), 34, 91-94, doi: 10.1192/pb.bp.108.021212

${ }^{1}$ East London NHS Foundation Trust: ${ }^{2}$ Oxleas NHS Foundation Trust; ${ }^{3}$ East London NHS Foundation Trust, St Bartholomew's Hospital

Correspondence to Robert Fisher (robert.fisher@eastlondon.nhs.uk)

\begin{abstract}
Aims and method Mental illness is associated with increased physical morbidity. We aimed to assess and improve the routine blood testing of prescribed antipsychotics in out-patients from a busy London inner city area. Audit findings were presented locally to prescribers, together with educational suggestions to improve physical health assessment.
\end{abstract}

Results Initially, the numbers monitored were low in the overall number of 126 patients included in the first audit. Following the intervention, this improved significantly in the second audit (of 106 patients).

Clinical implications A simple one-page monitoring prompt and an educational intervention could significantly increase the adherence to routine blood-testing guidelines. Better physical screening may help reduce physical morbidity and mortality, and improve the quality of life of individuals with mental illness.

Declaration of interest None.
Individuals with mental illness have markedly elevated rates of metabolic disturbance including obesity, diabetes and dyslipidaemia. ${ }^{1}$ In particular, individuals with schizophrenia have a $20 \%$ shorter life expectancy than the population at large. ${ }^{2}$ They have an increased relative risk of premature death, dying at least 10 years earlier than agematched individuals. ${ }^{3}$ This excess mortality has been largely attributed to 'natural causes' rather than suicide, ${ }^{3}$ but the health needs of people with schizophrenia who take antipsychotic medication are often not adequately addressed by clinicians, either in specialty mental health programmes or in primary care settings. ${ }^{2}$ The lack of consensus regarding which health parameters should be monitored has been a major obstacle to improving physical health monitoring, an issue that was addressed at the Mount Sinai Conference in New York. $^{2}$ 